\title{
Molecular markers in bladder cancer
}

\author{
Francesco Soria ${ }^{1,2} \cdot$ Laura-Maria Krabbe $^{3} \cdot$ Tilman Todenhöfer $^{4} \cdot$ Jakub Dobruch $^{5} \cdot$ Anirban P. Mitra $^{6}$. \\ Brant A. Inman ${ }^{7} \cdot$ Kilian M. Gust ${ }^{1} \cdot$ Yair Lotan ${ }^{3} \cdot$ Shahrokh F. Shariat ${ }^{1,3,8,9}$
}

Received: 29 May 2018 / Accepted: 20 September 2018 / Published online: 26 September 2018

(c) The Author(s) 2018

\begin{abstract}
Purpose Use of molecular markers in urine, tissue or blood offers potential opportunities to improve understanding of bladder cancer biology which may help identify disease earlier, risk stratify patients, improve prediction of outcomes or help target therapy.

Methods A review of the published literature was performed, without restriction of time.

Results Despite the fast-growing literature about the topic and the approval of several urinary biomarkers for use in clinical practice, they have not reached the level of evidence for widespread utilization. Biomarkers could be used in different clinical scenarios, mainly to overcome the limitations of current diagnostic, predictive, and prognostic tools. They have been evaluated to detect bladder cancer in asymptomatic populations or those with hematuria and in surveillance of disease as adjuncts to cystoscopy. There is also a potential role as prognosticators of disease recurrence, progression and survival both in patients with non-invasive cancers and in those with advanced disease. Finally, they promise to be helpful in predicting the response to local and/or systemic chemotherapy and/or immunotherapy.

Conclusions To date, due to the lack of high-quality prospective trials, the level of evidence provided by the current literature remains low and, therefore, the potential of biomarkers exceeds utilization in clinical practice.
\end{abstract}

Keywords Bladder cancer · Urinary biomarkers · Tissue biomarkers · Blood biomarkers · Guidelines

Shahrokh F. Shariat

shahrokh.shariat@meduniwien.ac.at

1 Department of Urology and Comprehensive Cancer Center, Vienna General Hospital, Medical University of Vienna, Währinger Gürtel 18-20, 1090 Vienna, Austria

2 Division of Urology, Department of Surgical Sciences, San Giovanni Battista Hospital, University of Studies of Torino, Turin, Italy

3 Department of Urology, University of Texas Southwestern Medical Center, Dallas, TX, USA

4 Department of Urology, Eberhard-Karls-University, Teubingen, Germany

5 Centre of Postgraduate Medical Education, Warsaw, Poland

6 Institute of Urology, University of Southern California, Los Angeles, CA, USA

7 Duke Cancer Institute, Duke University, Durham, NC, USA

8 Karl Landsteiner Institute of Urology and Andrology, Vienna, Austria

9 Department of Urology, Weill Cornell Medical College, New York, USA

\section{Introduction}

Bladder cancer $(\mathrm{BCa})$ is a heterogeneous disease with significant diagnostic, therapeutic and prognostic challenges [1]. The tools available to clinicians for diagnosis and staging require invasive procedures such as cystoscopy and biopsy in addition to imaging with computer tomography and magnetic resonance. These tools, however, often understage patients and lack sensitivity to detect all cancers (false negatives) and specifically micro-metastatic disease. These imprecisions in capturing the clinical and biologic potentials of a tumor result in over- and under-treatment with side effects of therapies [2].

Molecular markers detected in urine, tissue or blood offer promising opportunities to improve our understanding of biology of a specific cancer and its micro- and macroenvironment. This could help identify disease earlier, risk stratify patients, improve prognostication and prediction of outcomes and help target therapy. While some areas such as urine-based tumor markers have been more extensively studied, the current guidelines have yet to embrace markers in 
routine management of $\mathrm{BCa}$ [3]. In this consensus guideline, part of the SIU-ICUD update on BCa, we review the challenges of introducing markers into clinical care and discuss urine-, tissue- and blood-based markers for different stages of disease and different clinical scenarios. Evidence was selected through a non-systematic review of the literature.

\section{Challenges of marker introduction into clinical practice}

Biomarker research can be categorized, similar to drugdevelopment studies, into initial pre-clinical exploratory studies, clinical assay development and validation studies, small clinical retrospective studies, external validation in larger cohorts (retrospective or prospective, usually multiinstitutional), prospective clinical trials and further postapproval studies as well as possible expansion to other clinical scenarios and disease stages $[4,5]$. In an attempt to improve design, analysis and reporting of marker studies, a set of reporting recommendations has been developed and is generally accepted.

The main goal for marker development is to identify a validated test which can improve clinical decision-making in a cost-effective way. It is, therefore, not sufficient to merely show statistically significant independent association of the marker with the investigated outcome, but to show improved prognostic or predictive accuracy of a multivariable model over already available clinical features alone. Ideally, the integration of the marker should be improved with regard to discrimination, calibration and decision-analysis [5].

Finally, $\mathrm{BCa}$ is a heterogeneous disease. Therefore, it is unlikely that one single marker exists that can adequately characterize the potential and behavior of a cancer to allow reliable treatment conclusions. This has led many investigators to evaluate comprehensive pathways rather than single markers [6, 7]. Marker panels including drivers from key pathways in combination with clinical and pathological variables might be the most promising approach for accurate risk stratification and clinical decision-making for $\mathrm{BCa}$.

\section{Biomarkers according to clinical stages}

\section{Urinary biomarkers for screening and hematuria workup}

In patients without history of $\mathrm{BCa}$, there are several scenarios in which urinary biomarkers may play a role. One scenario that has frequently been discussed is the use of biomarkers for screening purposes. So far, the low prevalence of the disease in the general population has been a challenge for developing effective screening strategies [8]. Actually, the effectiveness of a screening program is significantly affected by the incidence and mortality of a specific disease. The number of trials applying biomarkers for $\mathrm{BCa}$ in a screening population is limited and, to date, there are no randomized controlled trials.

Identification of high-risk populations may help overcome these limitations [9]. However, data from recent trials indicate that even in patients with an increased risk of developing $\mathrm{BCa}$ such as workers exposed to occupational hazards with carcinogenic potential or heavy smokers, the incidence of $\mathrm{BCa}$ is too low for a broad screening to have a socioeconomic benefit. Lotan et al. [10], for example, assessed the value of NMP22 in a high-risk population including 1175 men and 327 women based on a history of at least 10 years of smoking or an occupational exposure of at least 15 years. Eighty-five (5.7\%) subjects had a positive NMP-22. Three from the 69 patients undergoing further evaluation had abnormal findings (one pTa low-grade tumor, one pTa highgrade tumor and one atypia). During long-term follow-up, only nine additional patients were diagnosed with $\mathrm{BCa}$ [11]. Of note, no patient had muscle-invasive cancer (MIBC) and a positive NMP22 was not associated with worse overall survival (OS).

A second clinical scenario in which urinary biomarkers may add value is in the risk stratifying patients with asymptomatic microhematuria (AMH). Patients with asymptomatic gross hematuria have a significant risk of $\mathrm{BCa}$ (approximately 10\%) making urologic workup necessary [12]. In these patients, urinary biomarkers could be used as an adjunct to cystoscopy and imaging but are currently unlikely to impact the diagnostic strategies. In patients with $\mathrm{AMH}$, international guidelines differ significantly on the optimal workup. The prevalence of AMH in the adult population ranges as high as $18 \%$, yet only $2 \%$ of the referred patients harbor BCa. This has led to a nonchalant general approach to AMH with limited workups and delayed referrals resulting in late diagnosis, especially in women [13]. In this setting, urinary biomarkers may help early identification of patients at risk triaging and fastening referral for a urologic workup $[12,14-16]$. Cha et al. performed a retrospective analysis of 1182 patients with hematuria, including $68 \%$ with $\mathrm{AMH}$ and evaluated cytology, imaging, cystoscopy, and immunocytology in all patients. A nomogram predicting the risk of $\mathrm{BCa}$ was constructed showing a predictive accuracy of $90.8 \%$ [17]. Lotan et al. [15] validated a nomogram incorporating age, gender, ethnicity, smoking history, type of hematuria, cytology and NMP22 BladderChek in a cohort of 381 subjects with hematuria. In total, 23 patients $(6.0 \%)$ had $\mathrm{BCa}$. The predictive accuracy of the nomogram was $80.2 \%$. Finally, in a cohort including 86 patients with $\mathrm{AMH}$ and 83 patients with gross hematuria, Beukert et al. [18] used methylation analysis of OSR1, SIM2, OTX1, MEIS1 and ONECUT2 for developing a model for prediction of BCa. 
The model also included clinicopathologic characteristics such as type of hematuria, age, gender and cytology results. The model yielded a sensitivity and specificity of $85 \%$ and $87 \%$ with an area under the curve (AUC) of $89 \%$.

While these studies suggest a potential benefit to urinary biomarkers in patients with AMH, prospective controlled trials are lacking and urgently needed. Moreover, so far, there is no evidence that the use of urinary biomarkers in a screening/early detection setting has an effect on cancer-specific mortality [3]. Therefore, due to the low levels of evidence (LoE) provided, urinary biomarkers are currently not recommended for the screening of $\mathrm{BCa}$ or in prioritization of patients with AMH.

\section{Urinary biomarkers in surveillance setting}

Urinary biomarkers in surveillance setting have been developed to overcome the limitations of cystoscopy and urine cytology. The former is invasive and may miss significant proportion of cancer recurrences, especially CIS, whereas the latter has low sensitivity in low-/intermediate-risk nonmuscle-invasive bladder cancer (NMIBC) and suffers from considerable inter- and intra-observer variabilities especially in patients after BCG immunotherapy [19-21]. Biomarker implementation in surveillance may be categorized with two potential applications: (1) as an adjunct to cystoscopy and (2) its substitute. Furthermore, the role of a biomarker in clinical decision-making would be different in low-/intermediate-risk NMIBC and in high-risk NMIBC. In patients with low-grade disease it is possible that a marker could reduce the number of cystoscopies needed. For high-grade cancers, the marker would be an adjunct to cystoscopy and an abnormal result would increase awareness of patients and physicians, identify those at risk of progression, facilitate the interpretation of indeterminate results of cytology and assess response to BCG.

A urine marker would need a very high sensitivity and negative predictive value (NPV) to replace cystoscopy. One recent survey suggests that patient preference would have sensitivity as high as $\mathbf{9 0 - 9 5 \%}$ for a marker to replace cystoscopy [22]. Overall, reported sensitivities of voided urine cytology, NMP22 (nuclear matrix protein), BTA (bladder tumor antigen) stat and BTA trak, Immunocyt, UBC test, Cyfra 21-1, FISH (fluorescence in situ hybridization) and Cxbladder Monitor in this setting differ widely between trials, ranging from $7 \%$ to $93 \%$ [23, 24]. Similarly, corresponding specificities range from $49 \%$ to $99 \%$ [25, 26]. Of these biomarkers, only Cxbladder Monitor has shown a high sensitivity (91-93\%) while its rate of false-negative results does not exceed 1.5\% [24]. Both metrics are believed to be prerequisites for the test to supplant cystoscopy. However, for low-grade tumors it may be less clinically relevant if a small tumor is missed by either cystoscopy or a marker.

Due to the unsatisfactory performances of most single biomarkers, panels of markers have been used to improve sensitivity or alternatively combining markers. One study found that combining two tests among cytology, immunocytology, FISH and NMP22 resulted in sensitivity and negative predictive value of no greater than $89.8 \%$ (Immunocyt + NMP22) and 92.1\% (FISH + Immunocyt) [27]. If cytology is supplemented with any of the four tests, corresponding values are no greater than $86.7 \%$ (NMP22) and 91.3\% (immunocytology). Adding FISH to conventional urine cytology is associated with $80.5 \%$ sensitivity $(94.0 \%$ for high-risk tumors) and $90.1 \%$ negative predictive value (98.8\% for high-risk tumors).

Based on these findings, the European (EAU), the American Urological Associations (AUA) as well as the Society of Urologic Oncology (SUO) do not recommend urinary biomarkers yet for the routine surveillance of patients with NMIBC [28, 29]. According to AUA/SUO Guideline "clinician may use biomarkers to assess response to intravesical BCG (UroVysion ${ }^{\circledR}$ FISH) and adjudicate equivocal cytology (UroVysion® FISH and ImmunoCyt $\left.{ }^{\circledR}\right)$ " [29]. Actually, serial measurements of UroVysion FISH in patients subjected to BCG therapy revealed that abnormal test results at baseline (before BCG), at 6 weeks (before the $6^{\text {th }}$ BCG instillation) and before the 3 months' cystoscopy (before the first maintenance course) are significantly associated with both cancer recurrence and progression. FISH at 3 months identified $50 \%$ of patients who experienced cancer progression within 2 years in half of those with positive test compared to only $3 \%$ of those who had normal result [30].

Another approach toward improving surveillance protocols of NMIBC and optimizing costs is to use reflex testing. In patients with negative/uncertain result of one test, the accuracy of follow-up is significantly increased by adding subsequent highly sensitive biomarkers. Immunotherapy is known to evoke inflammatory changes within the bladder often making reliable assessment of the lower urinary tract challenging. As such, accuracy of cytology used as an adjunct to cystoscopy to increase the detection of CIS or upper tract lesions is hampered by BCG. FISH and ImmunoCyt ${ }^{\circledR}$ were investigated in patients with atypical cytology. UroVysion FISH has $100 \%$ sensitivity and $100 \%$ negative predictive value in those with negative cystoscopy, yet equivocal cytology [31]. ImmunoCyt has $73 \%$ sensitivity in detecting recurrent bladder tumor in patients with atypical cytology with corresponding negative predictive value of $80 \%$ [32]. In summary, both tests are recognized by AUA/ SUO as the potential reflex biomarkers to adjudicate atypical cytology to help avoid unnecessary workups.

In summary, in the surveillance of patients with NMIBC, there is insufficient evidence that urinary biomarkers can 
replace cystoscopy and prospective studies are necessary to demonstrate whether this is safe. Urinary biomarkers, however, could be used to help assess the response to intravesical immunotherapy and as reflex test in cases with equivocal urinary cytology (Expert Opinion).

\section{Tissue biomarkers for non-muscle-invasive bladder cancer}

Tissue biomarkers can theoretically be used in NMIBC to predict oncological outcomes such as recurrence and progression as well as the response to intravesical BCG and, ideally, could be used to improve individualized treatment and surveillance based on individualized risk profiles. Moreover, they can be useful to identify the proportion of high-risk NMIBC patients who are likely to develop disease progression to invasive disease, thus requiring consideration for intensified therapy such as early radical cystectomy.

To date biomarkers associated with pathways important for tumor growth and spread have been evaluated intensively, such as cycle cell regulators, angiogenesis, apoptosis, signaling proteins and hormones.

$\mathrm{p} 53$, the product of TP53, the most common oncosuppressor gene mutated in all human cancers, has been associated with features of tumor aggressiveness and correlated with poor oncological outcomes [6, 33-37]. Moreover, it is associated with the most aggressive T1G3 cancers. Two meta-analyses summarizing the role of p53 in NMIBC showed that its overexpression can predict progression in T1HG patients but is not able to predict the response to BCG therapy $[38,39]$. However, the heterogeneity of the included studies and limitations related to the immunohistochemistry hampered any clear conclusions [38].

The association between an altered expression of the tumor suppressor retinoblastoma $(\mathrm{Rb})$ and oncological outcomes in $\mathrm{BCa}$ is relatively weak and the majority of trials failed to find an association with recurrence and progression [40]. More recently, it has been shown that Rb could be of predictive utility for $\mathrm{BCa}$ recurrence and progression only when combined with other biomarkers such as p53 and p27 $[6,34]$ in a panel of markers.

The antiapoptotic biomarker survivin was found to predict recurrence, progression and survival [41, 42]. In the largest series, Fristrup et al. [43] analyzed the expression of survivin in 283 NMIBC patients and reported a strong association with recurrence, progression and OS. Recently, a meta-analysis of 14 studies reported a statistically significant association with recurrence, cancer-specific survival (CSS), and OS [44]. However, prospective large series are lacking. Other biomarkers of apoptosis such as Livin, Bcl-2 and Bax have been investigated, but there are few studies $[45,46]$. Finally, cell signaling pathway biomarkers such as
ErbB and FGFR family members as well as angiogenesis (VEGF, MVD, HIF-1 $\alpha$ ) and tumor cell invasion biomarkers (E-cadherin and N-cadherin) have been shown to be related to outcomes of NMIBC [47, 48].

Based on the current literature, one can conclude that none of the evaluated tissue biomarkers alone could be used to predict oncological outcomes with sufficient accuracy to change decisions in routine clinical practice. Therefore, it has been postulated that a panel of biomarkers could improve the predictive accuracy over clinical information alone [49, 50]. However, even in this setting, results are conflicting and, therefore, to date, due to the low level of evidence and to the contrasting reported findings, the use of tissue biomarkers in $\mathrm{BCa}$ is not recommended since it does not change/improve clinical decision-making.

\section{Blood and tissue biomarkers for invasive bladder cancer}

\section{Tissue-based biomarkers}

The development of MIBC involves alterations in multiple homeostatic pathways with profound deregulations within a complex molecular circuitry. Therefore, these alterations can serve as prognosticators of outcomes, predictors of response to therapy, and they may also act as therapeutic targets.

Several retrospective studies have reported that nuclear accumulation of p53 is prognostic in MIBC, especially in patients treated with radical cystectomy [51, 52]. However, at this time, the use of p53 as a prognostic biomarker in MIBC is still not clinically established despite over 100 studies evaluating its utility. Actually, a phase III trial designed to evaluate the benefit of stratifying organ-confined invasive BCa patients based on their $\mathrm{p} 53$ status for adjuvant cisplatinbased chemotherapy could not confirm the prognostic value of the p53 alteration [53].

Inactivating mutation of $\mathrm{Rb}$, in conjunction with other cell cycle regulatory proteins, has been shown to be prognostic in MIBC [54]. Combined immunohistochemical assessment of p53, p21, Rb, cyclin E1 and p27 has been shown to yield predictive accuracies superior to that of any single biomarker in patients with $\mathrm{BCa}$ treated with radical cystectomy, and improving risk stratification by a significant prognostic margin [55-57].

As in NMIBC, apoptosis biomarkers such as survivin and Bcl-2 family are associated with outcomes in MIBC [7]. Interestingly, the proportion of specimens with survivin overexpression increases progressively from NMIBC to MIBC and to metastatic lymph node tissue [41]. In a large multicenter international validation study, addition of survivin significantly improved the accuracy of standard clinicopathologic features for prediction of disease recurrence and CSS in a subgroup of patients with pT1-3N0M0 
disease [58]. Proliferation and angiogenesis biomarkers such as Ki67, VEGF and microvessel density have been associated with higher pathologic stage, lymphovascular invasion, lymph node metastasis, disease recurrence and CSS [59-62].

Finally, tissue-based gene- and transcriptome-level profiling has been used to identify biomarkers that characterize and can potentially predict prognosis in patients with MIBC [63]. Comprehensive characterization of the genomic landscape of BCa through efforts of The Cancer Genome Atlas Research Network resulted in identification of four expression clusters of high-grade MIBC [64]. Tumors in cluster I had papillary-like morphology with increased FGFR3 expression, mutations and copy number gain, thereby suggesting that these patients may respond to FGFR inhibitors or its downstream targets. These tumors also showed decreased miR-99a and miR-100 expressions, which in turn downregulate FGFR3 expression [65]. Tumors in clusters I and II have similar features to those of luminal A breast cancer, with high expression of luminal breast differentiation markers, including GATA3 and FOXA1. These tumors also harbor increased expression of uroplakins, E-cadherin and members of the miR-200 family. Increased expression of $E R B B 2$ and estrogen receptor- $\beta$ by these tumors also suggested that they may serve as potential targets for hormonal therapies. Expression signature of tumors in cluster III ('basal/squamous-like') were similar to that of basal-like breast cancers and squamous cell cancers of the head and neck and lung, characterized by overexpression of epithelial lineage genes. These findings suggest the presence of distinct molecular subtypes of MIBC with characteristic expression signatures, which may impact prognosis and serve as candidates for selective therapeutic strategies [66].

\section{Blood-based biomarkers}

Assessment of biomarkers in blood offers several advantages over tissue samples, such as ease of procurement, minimally invasive collection method, and higher sample homogeneity. However, clinical applicability and value of these biomarkers in the setting of MIBC remain to be further tested and validated in large well-controlled multi-institutional studies.

Biomarkers associated with cellular proliferation such as insulin growth factor binding proteins (IGFBPs) play a central role in regulating cellular growth, proliferation and transformation. IGFBP-3 is a member of this family that also has its own pro-apoptotic effects. Lower preoperative plasma levels of IGFBP-3 are a significant predictor of lymph node involvement in patients undergoing radical cystectomy and also portended a significantly increased risk of disease recurrence and cancer-specific mortality [67]. Similarly, elevated preoperative plasma levels of transforming growth factor $-\beta 1$ (TGF- $\beta 1$ ) protein have been associated with lymphovascular invasion, nodal and distant metastasis, disease recurrence and CSS $[68,69]$.

Inflammation and immune biomarkers such as interleukin-6 and C-reactive protein (the most widely studied serum marker for inflammation in $\mathrm{BCa}$ ) have been consistently associated with adverse survival outcomes [70-72]. In line with observations, elevated serum levels of VEGF have also been associated with high stage and grade, lymphovascular invasion, metastases, and poor CSS [73].

The presence of circulating tumor cells (CTCs) in peripheral blood may represent an early step in the metastatic progression of $\mathrm{BCa}$. In an evaluation of 55 patients undergoing radical cystectomy, the presence of CTCs was associated with survival. The study noted that patients with one or more CTCs had a shorter time to disease recurrence and shorter CSS than those with none [74]. These findings were are also found in a larger cohort of 100 consecutive patients with non-metastatic $\mathrm{BCa}$ undergoing radical cystectomy [75].However, despite these encouraging results, the use of blood- and tissue-based biomarkers for prediction and guidance of clinical decision-making in MIBC is still too immature due to the weak strength of evidence of published studies. Larger prospective cohorts will be important to validate these results.

\section{Response to systemic therapy}

\section{Response to systemic chemotherapy}

In $\mathrm{BCa}$, chemotherapy can be administered intravesically (usually for NMIBC) or systemically (for MIBC and metastatic $\mathrm{BCa}$ ). Prediction of response to chemotherapies could be helpful for decision regarding type and timing of systemic and local therapies.

A hallmark of cancer, including $\mathrm{BCa}$, is dysregulation of the cell cycle which results in the sustained signal for proliferation required for cancer development. Several cell cycle regulators and markers of proliferation have been tested as predictors of chemotherapy response such as CyclinD1, CCDN1 and Ki-67. A second hallmark of cancers is their ability to escape apoptosis, a process controlled by caspases. Caspases, in turn, are regulated by several molecules involved in the detection of DNA or mitochondrial damage, including p53 and Bcl-2. p53 has been extensively tested in $\mathrm{BCa}$, both as a prognostic biomarker and as a predictor of treatment response. While initial retrospective studies were promising, randomized trial results showed no role for $\mathrm{p} 53$ as a predictor of chemotherapy response $[53,76]$.

Many chemotherapy agents work by causing DNA damage and, if its DNA integrity is sufficiently disrupted, the cancer cell cannot replicate. Cancer cells that have deficient DNA damage repair mechanisms are unable to fix 
the damage induced by these chemotherapy agents and are, therefore, more susceptible to being killed by the agents. Proteins involved in DNA damage detection and repair that play a role in BCa chemotherapy response include BRCA-1, BRCA-2, RAD51, PARP1, ERCC1, ERCC2, ATM, RB1, and FANCC. In the study by Plimack et al., response to neoadjuvant chemotherapy (NAC) before radical cystectomy (stage $\mathrm{T} 1$ or less at surgery) was associated with an alteration in ATM, RB1 or FANCC [77]. Similarly, in a validation study on the role of ERCC2, ERCC2 mutation was present in $80 \%$ of patients who had pathologic stage $\mathrm{T} 1$ or less at time of radical cystectomy after NAC (i.e., responders) [78, 79].

It has been known for decades that the mitogenic signals derived from the binding of growth factors to their receptors are crucial for cancer development. Many growth factors and growth factor receptors signal into the cell via transmembrane tyrosine kinases, and these kinases are the targets of several new systemic therapies in oncology (such as lapatinib, pazopanib, and sunitinib). While these three drugs appear to have limited activity in BCa, the possibility of biomarker enrichment for response has been assessed [80]. Finally, microRNAs' expression, germline single nucleotide polymorphisms, DNA ploidy, S-phase fraction (a proliferative index) and immune markers such as lymphocyte count and interleukin- 8 have been preliminarily tested as predictors of chemotherapy response.

Based on the current data, none of the biomarkers has reached the level of evidence sufficient to determine therapeutic approach and resistance to targeted chemotherapies. Ongoing, biomarker-driven trials will shine more light on this important issue.

\section{Response to systemic immunotherapy}

Over the last years, immunotherapies have proven unprecedented activity in $\mathrm{BCa}$ after failure of cisplatin-based therapies or in patients not suitable to receive cisplatin-based chemotherapy. Inhibition of immune checkpoints has been shown for several agents targeting programmed death-1 (PD-1) receptor or its ligand (PD-L1) and cytotoxic T-lymphocyte antigen 4 (CTLA-4). Nevertheless, the majority of patients still do not respond to treatment [81-88], which results in a significant financial burden and potential treatment-related side effects to patients who do not benefit from therapy. Therefore, biomarkers are needed to predict those most likely to benefit from checkpoint targeting therapy.

The expression of T-cell coregulatory proteins is altered in a large proportion of $\mathrm{BCa}$ with differential upregulation in cancer versus normal urothelium, and an association of B7-H1 with mortality after radical cystectomy in organconfined disease has been shown [89]. Detection of PD-L1 on tumor samples with immunohistochemistry (IHC) has been used by several clinical trials to evaluate the feasibility of PD-L1 expression as a predictive biomarker. Since testing for PD-L1 is not standardized, the evaluation of PD-L1 has several limitations. The cisplatin-pretreated arm (cohort 2) of the Imvigor 210 trial revealed an association between objective response rate (ORR) to atezolizumab and PD-L1 expression status (ORR was $27 \%$ in patients with PD-L1-positive immune cells $\geq 5 \%$ vs $18 \%$ in those with PD-L1-positive immune cells $\geq 1 \%$ vs $15 \%$ in all patients [81]. However, in the cisplatin-ineligible arm, the ORR was independent of PD-L1 status [84]. Conversely, in the CheckMate 032 study, there was no difference in ORR between patients with PD-L1 expression $<1 \%$ and those with PD-L1 expression $\geq 1 \%$ (26.2\% vs $24.0 \%$, respectively) [87], CheckMate 275 , evaluating nivolumab in metastatic urothelial carcinoma after platinum therapy, confirmed the association (ORR of 28.4, 23.8 and $16.1 \%$ in patients with PD-L1 expression of $5 \%$ or greater, $1 \%$ or greater and less than $1 \%$, respectively) [82]. Finally, in KEYNOTE-045 trial, the benefit of pembrolizumab appeared to be independent of PD-L1 expression on tumor and infiltrating immune cells [83]. Spatial, time and heterogeneity are limiting factors in PD-1 biomarkers [90].

Molecular subtypes of MIBC have recently been categorized based on gene expression. The Cancer Genome Atlas (TCGA) [64] described four subtypes of BCa based on cluster analysis of messenger RNA (mRNA). The exploratory analyses from cisplatin pretreated arm of the Imvigor 210 trial showed TCGA subtypes to be independently predictive for response to atezolizumab treatment [81]. Response to atezolizumab occurred in all TCGA subtypes but was significantly higher in the luminal cluster II subtype than in other subtypes [81]. For cisplatin-ineligible patients, responses were seen across all subtypes and were more frequent with the luminal II subtype [84]. Conversely, in CheckMate 275, basal 1 subtype contained the highest proportion of responders [82].

High mutational load may be associated with better response to immunotherapy, particularly for checkpoint inhibitors, with some trials (such as Imvigor 210) showing a correlation between patients with a higher mutational burden and better responses to immunotherapeutic agents [81]. Finally, gene expression profiling (such as Interferon y gene signature) and changes in tumor microenvironment (such as chemokines and CD8 $+\mathrm{T}$-cell infiltration) are promising predictors of response to immunotherapy [81, 82].

Despite these promising findings, use of biomarkers to predict the response to systemic immunotherapy remains limited; indeed, a significant proportion of patients with negative biomarkers status still respond to treatment and many patients with positive biomarkers status fail to respond. 


\section{Conclusions}

Despite the plethora of studies investigating the role of urinary, blood and tissue biomarkers in $\mathrm{BCa}$ with an ever-rising rate of data, none of the studies have reached the required level of evidence to change clinical practice and, therefore, none is widely used or to be recommended. Except for some specific clinical scenarios where biomarkers can be used as an adjunct in the clinical setting, use of biomarkers in $\mathrm{BCa}$ remains experimental and is still not recommended in clinical practice. However, biomarkers are the basis for the individualized medicine and represent undoubtedly the future of $\mathrm{BCa}$ treatment.

Acknowledgements Open access funding provided by Medical University of Vienna.

Author contributions Protocol/project development: SF, LY and SSF. Data collection or management: SF, SSF, KL-M, TT, IB, DJ, GKM, MAP and LY. Data analysis: SF, LY and SSF. Manuscript writing/ editing: SF, LY and SSF wrote the manuscript; SF, SSF, KL-M, TT, IB, DJ, GKM, MAP and LY edited the manuscript.

\section{Compliance with ethical standards}

Conflict of interest I certify that all conflicts of interest, including specific financial interests and relationships and affiliations relevant to the subject matter or materials discussed in the manuscript are the following: Shahrokh Shariat owns or co-owns the following patents: methods to determine prognosis after therapy for prostate cancer, granted 2002-09-06; methods to determine prognosis after therapy for bladder cancer, granted 2003-06-19; prognostic methods for patients with prostatic disease, granted 2004-08-05; soluble Fas: urinary marker for the detection of bladder transitional cell carcinoma, granted 2010-07-20. $\mathrm{He}$ is an advisory board member of Astellas, Cepheid, Ipsen, Jansen, Lilly, Olympus, Pfizer, Pierre Fabre, Sanofi, and Wolff. He is a speaker for Astellas, Ipsen, Jansen, Lilly, Olympus, Pfizer, Pierre Fabre, Sanochemia, Sanofi and Wolff.

Ethical standards This study was conducted according to the Declaration of Helsinki.

Open Access This article is distributed under the terms of the Creative Commons Attribution 4.0 International License (http://creativeco mmons.org/licenses/by/4.0/), which permits unrestricted use, distribution, and reproduction in any medium, provided you give appropriate credit to the original author(s) and the source, provide a link to the Creative Commons license, and indicate if changes were made.

\section{References}

1. Kamat AM, Hegarty PK, Gee JR, Clark PE, Svatek RS, Hegarty $\mathrm{N}$ et al (2013) ICUD-EAU international consultation on bladder cancer 2012: screening, diagnosis, and molecular markers. Eur Urol 63:4-15. https://doi.org/10.1016/j.eururo.2012.09.057

2. Karakiewicz PI, Shariat SF, Palapattu GS, Perrotte P, Lotan Y, Rogers CG et al (2006) Precystectomy nomogram for prediction of advanced bladder cancer stage. Eur Urol 50:1254-1260. https ://doi.org/10.1016/j.eururo.2006.06.010 (Discussion 1261-2)

3. Tilki D, Burger M, Dalbagni G, Grossman HB, Hakenberg OW, Palou J et al (2011) Urine markers for detection and surveillance of non-muscle-invasive bladder cancer. Eur Urol 60:484-492. https://doi.org/10.1016/j.eururo.2011.05.053

4. Bensalah K, Montorsi F, Shariat SF (2007) Challenges of cancer biomarker profiling. Eur Urol 52:1601-1609. https://doi. org/10.1016/j.eururo.2007.09.036

5. Shariat SF, Lotan Y, Vickers A, Karakiewicz PI, Schmitz-Drager BJ, Goebell PJ et al (2010) Statistical consideration for clinical biomarker research in bladder cancer. Urol Oncol 28:389-400. https://doi.org/10.1016/j.urolonc.2010.02.011

6. Shariat SF, Zlotta AR, Ashfaq R, Sagalowsky AI, Lotan Y (2007) Cooperative effect of cell-cycle regulators expression on bladder cancer development and biologic aggressiveness. Mod Pathol 20:445-459. https://doi.org/10.1038/modpathol.3800757

7. Karam JA, Lotan Y, Karakiewicz PI, Ashfaq R, Sagalowsky AI, Roehrborn CG et al (2007) Use of combined apoptosis biomarkers for prediction of bladder cancer recurrence and mortality after radical cystectomy. Lancet Oncol 8:128-136. https://doi. org/10.1016/S1470-2045(07)70002-5

8. Friedman GD, Hiatt RA, Quesenberry CP Jr, Selby JV, Weiss NS (1995) Problems in assessing screening experience in observational studies of screening efficacy: example of urinalysis screening for bladder cancer. J Med Screen 2:219-223. https:// doi.org/10.1177/096914139500200409

9. Krabbe L-M, Svatek RS, Shariat SF, Messing E, Lotan Y (2015) Bladder cancer risk: use of the PLCO and NLST to identify a suitable screening cohort. Urol Oncol 33:65.e19-65.e25. https ://doi.org/10.1016/j.urolonc.2014.06.009

10. Lotan Y, Elias K, Svatek RS, Bagrodia A, Nuss G, Moran B et al (2009) Bladder cancer screening in a high risk asymptomatic population using a point of care urine based protein tumor marker. J Urol 182:52-57. https://doi.org/10.1016/j. juro.2009.02.142 (Discussion 58)

11. Starke N, Singla N, Haddad A, Lotan Y (2016) Long-term outcomes in a high-risk bladder cancer screening cohort. BJU Int 117:611-617. https://doi.org/10.1111/bju.13154

12. Mariani AJ, Mariani MC, Macchioni C, Stams UK, Hariharan A, Moriera A (1989) The significance of adult hematuria: 1000 hematuria evaluations including a risk-benefit and cost-effectiveness analysis. J Urol 141:350-355

13. Fajkovic H, Halpern JA, Cha EK, Bahadori A, Chromecki TF, Karakiewicz PI et al (2011) Impact of gender on bladder cancer incidence, staging, and prognosis. World J Urol 29:457-463. https://doi.org/10.1007/s00345-011-0709-9

14. Cohen RA, Brown RS (2003) Clinical practice. Microscopic hematuria. N Engl J Med 348:2330-2338. https://doi. org/10.1056/NEJMcp012694

15. Lotan Y, Svatek RS, Krabbe LM, Xylinas E, Klatte T, Shariat SF (2014) Prospective external validation of a bladder cancer detection model. J Urol 192:1343-1348. https://doi. org/10.1016/j.juro.2014.05.087

16. Elias K, Svatek RS, Gupta S, Ho R, Lotan Y (2010) High-risk patients with hematuria are not evaluated according to guideline recommendations. Cancer 116:2954-2959. https://doi. org/10.1002/cncr. 25048

17. Cha EK, Tirsar LA, Schwentner C, Christos PJ, Mian C, Hennenlotter J et al (2012) Immunocytology is a strong predictor of bladder cancer presence in patients with painless hematuria: a multicentre study. Eur Urol 61:185-192. https://doi. org/10.1016/j.eururo.2011.08.073

18. Beukers W, Kandimalla R, van Houwelingen D, Kovacic H, Chin JF, Lingsma HF et al (2013) The use of molecular analyses in voided urine for the assessment of patients with 
hematuria. PLoS One 8:e77657. https://doi.org/10.1371/journ al.pone. 0077657

19. van der Aa MNM, Steyerberg EW, Bangma C, van Rhijn BWG, Zwarthoff EC, van der Kwast TH (2010) Cystoscopy revisited as the gold standard for detecting bladder cancer recurrence: diagnostic review bias in the randomized, prospective CEFUB trial. J Urol 183:76-80. https://doi.org/10.1016/j.juro.2009.08.150

20. Messer J, Shariat SF, Brien JC, Herman MP, Ng CK, Scherr DS et al (2011) Urinary cytology has a poor performance for predicting invasive or high-grade upper-tract urothelial carcinoma. BJU Int 108:701-705. https://doi.org/10.1111/j.1464410X.2010.09899.x

21. Karakiewicz PI, Benayoun S, Zippe C, Lüdecke G, Boman H, Sanchez-Carbayo M et al (2006) Institutional variability in the accuracy of urinary cytology for predicting recurrence of transitional cell carcinoma of the bladder. BJU Int 97:997-1001. https ://doi.org/10.1111/j.1464-410X.2006.06036.x

22. Yossepowitch O, Herr HW, Donat SM (2007) Use of urinary biomarkers for bladder cancer surveillance: patient perspectives. J Urol 177:1277-1282. https://doi.org/10.1016/j.juro.2006.11.066 (Discussion 1282)

23. Miyanaga N, Akaza H, Tsukamoto S, Shimazui T, Ohtani M, Ishikawa S et al (2003) Usefulness of urinary NMP22 to detect tumor recurrence of superficial bladder cancer after transurethral resection. Int J Clin Oncol 8:369-373. https://doi.org/10.1007/ s10147-003-0357-1

24. Kavalieris L, O'Sullivan P, Frampton C, Guilford P, Darling D, Jacobson E et al (2017) Performance characteristics of a multigene urine biomarker test for monitoring for recurrent urothelial carcinoma in a multicenter study. J Urol 197:1419-1426. https:// doi.org/10.1016/j.juro.2016.12.010

25. Horstmann M, Patschan O, Hennenlotter J, Senger E, Feil G, Stenzl A (2009) Combinations of urine-based tumour markers in bladder cancer surveillance. Scand J Urol Nephrol 43:461-466. https://doi.org/10.3109/00365590903296837

26. Babjuk M, Soukup V, Pešl M, Koštîrová M, Drncová E, Smolová $\mathrm{H}$ et al (2008) Urinary cytology and quantitative BTA and UBC tests in surveillance of patients with pTapT1 bladder urothelial carcinoma. Urology 71:718-722. https://doi.org/10.1016/j.urolo gy.2007.12.021

27. Todenhöfer T, Hennenlotter J, Esser M, Mohrhardt S, Aufderklamm S, Böttge J et al (2014) Stepwise application of urine markers to detect tumor recurrence in patients undergoing surveillance for non-muscle-invasive bladder cancer. Dis Markers 2014:973406. https://doi.org/10.1155/2014/973406

28. Babjuk M, Böhle A, Burger M, Capoun O, Cohen D, Compérat EM et al (2016) EAU guidelines on non-muscle-invasive urothelial carcinoma of the bladder: update. Eur Urol 71:447-461. https ://doi.org/10.1016/j.eururo.2016.05.041

29. Chang SS, Boorjian SA, Chou R, Clark PE, Daneshmand S, Konety BR et al (2016) Diagnosis and treatment of non-muscle invasive bladder cancer: AUA/SUO guideline. J Urol 196:10211029. https://doi.org/10.1016/j.juro.2016.06.049

30. Kamat AM, Willis DL, Dickstein RJ, Anderson R, NoguerasGonzález G, Katz RL et al (2016) Novel fluorescence in situ hybridization-based definition of bacille Calmette-Guérin (BCG) failure for use in enhancing recruitment into clinical trials of intravesical therapies. BJU Int 117:754-760. https://doi.org/10.1111/ bju. 13186

31. Schlomer BJ, Ho R, Sagalowsky A, Ashfaq R, Lotan Y (2010) Prospective validation of the clinical usefulness of reflex fluorescence in situ hybridization assay in patients with atypical cytology for the detection of urothelial carcinoma of the bladder. J Urol 183:62-67. https://doi.org/10.1016/j.juro.2009.08.157

32. Odisho AY, Berry AB, Ahmad AE, Cooperberg MR, Carroll PR, Konety BR (2013) Reflex ImmunoCyt testing for the diagnosis of bladder cancer in patients with atypical urine cytology. Eur Urol 63:936-940. https://doi.org/10.1016/j.eururo.2012.04.019

33. Shariat SF, Weizer AZ, Green A, Laucirica R, Frolov A, Wheeler TM et al (2000) Prognostic value of P53 nuclear accumulation and histopathologic features in $\mathrm{T} 1$ transitional cell carcinoma of the urinary bladder. Urology 56:735-740

34. Shariat SF, Ashfaq R, Sagalowsky AI, Lotan Y (2007) Predictive value of cell cycle biomarkers in nonmuscle invasive bladder transitional cell carcinoma. J Urol 177:481-487. https://doi. org/10.1016/j.juro.2006.09.038 (Discussion 487)

35. Shariat SF, Chade DC, Karakiewicz PI, Ashfaq R, Isbarn H, Fradet Y et al (2010) Combination of multiple molecular markers can improve prognostication in patients with locally advanced and lymph node positive bladder cancer. J Urol 183:68-75. https ://doi.org/10.1016/j.juro.2009.08.115

36. Shariat SF, Kim J, Raptidis G, Ayala GE, Lerner SP (2003) Association of $\mathrm{p} 53$ and $\mathrm{p} 21$ expression with clinical outcome in patients with carcinoma in situ of the urinary bladder. Urology 61:1140-1145

37. Fritsche H-M, Burger M, Svatek RS, Jeldres C, Karakiewicz PI, Novara G et al (2010) Characteristics and outcomes of patients with clinical T1 grade 3 urothelial carcinoma treated with radical cystectomy: results from an international cohort. Eur Urol 57:300-309. https://doi.org/10.1016/j.eururo.2009.09.024

38. Du J, Wang S, Yang Q, Chen Q, Yao X (2016) p53 status correlates with the risk of progression in stage T1 bladder cancer: a meta-analysis. World J Surg Oncol 14:137. https://doi. org/10.1186/s12957-016-0890-9

39. Zhou X, Zhang G, Tian Y (2015) p53 status correlates with the risk of recurrence in non-muscle invasive bladder cancers treated with bacillus Calmette-Guérin: a meta-analysis. PLoS One 10:e0119476. https://doi.org/10.1371/journal.pone.0119476

40. Tetu B, Fradet Y, Allard P, Veilleux C, Roberge N, Bernard P (1996) Prevalence and clinical significance of HER/2neu, p53 and $\mathrm{Rb}$ expression in primary superficial bladder cancer. $\mathrm{J}$ Urol 155:1784-1788

41. Shariat SF, Ashfaq R, Karakiewicz PI, Saeedi O, Sagalowsky AI, Lotan Y (2007) Survivin expression is associated with bladder cancer presence, stage, progression, and mortality. Cancer 109:1106-1113. https://doi.org/10.1002/cncr.22521

42. Shariat SF, Lotan Y, Saboorian H, Khoddami SM, Roehrborn CG, Slawin KM et al (2004) Survivin expression is associated with features of biologically aggressive prostate carcinoma. Cancer 100:751-757. https://doi.org/10.1002/cncr.20039

43. Fristrup N, Ulhøi BP, Birkenkamp-Demtröder K, Mansilla F, Sanchez-Carbayo M, Segersten U et al (2012) Cathepsin E, maspin, Plk1, and survivin are promising prognostic protein markers for progression in non-muscle invasive bladder cancer. Am J Pathol 180:1824-1834. https://doi.org/10.1016/j.ajpat h.2012.01.023

44. Jeon C, Kim M, Kwak C, Kim HH, Ku JH (2013) Prognostic role of survivin in bladder cancer: a systematic review and metaanalysis. PLoS One 8:e76719. https://doi.org/10.1371/journ al.pone. 0076719

45. Xi RC, Sheng YR, Chen WH, Sheng L, Gang JJ, Tong $\mathrm{Z}$ et al (2013) Expression of survivin and livin predicts early recurrence in non-muscle invasive bladder cancer. J Surg Oncol 107:550554. https://doi.org/10.1002/jso.23272

46. Ajili F, Kaabi B, Darouiche A, Tounsi H, Kourda N, Chebil M et al (2012) Prognostic value of Bcl-2 and Bax tumor cell expression in patients with non muscle-invasive bladder cancer receiving bacillus Calmette-Guerin immunotherapy. Ultrastruct Pathol 36:31-39. https://doi.org/10.3109/01913123.2011.620221

47. Byrne RR, Shariat SF, Brown R, Kattan MW, Morton RAJR, Wheeler TM et al (2001) E-cadherin immunostaining of bladder 
transitional cell carcinoma, carcinoma in situ and lymph node metastases with long-term followup. J Urol 165:1473-1479

48. Xylinas E, Kluth LA, Lotan Y, Daneshmand S, Rieken M, Karakiewicz PI et al (2014) Blood- and tissue-based biomarkers for prediction of outcomes in urothelial carcinoma of the bladder. Urol Oncol 32:230-242. https://doi.org/10.1016/j.urolonc.2013.06.009

49. Zlotta A, Alkhateeb S, Neill M, Bar-Moshe S, Rhijn B, Kakiashvili D et al (2011) Long-term prognostic value of the combination of EORTC risk group calculator and molecular markers in non-muscle-invasive bladder cancer patients treated with intravesical bacille Calmette-Guérin. Urol Ann 3:119. https://doi. org/10.4103/0974-7796.84954

50. Passoni N, Gayed B, Kapur P, Sagalowsky AI, Shariat SF, Lotan Y (2016) Cell-cycle markers do not improve discrimination of EORTC and CUETO risk models in predicting recurrence and progression of non-muscle-invasive high-grade bladder cancer. Urol Oncol Semin Orig Investig 34:485.e7-485.e14. https://doi. org/10.1016/j.urolonc.2016.05.014

51. Shariat SF, Tokunaga H, Zhou J, Kim J, Ayala GE, Benedict WF et al (2004) p53, p21, pRB, and p16 expression predict clinical outcome in cystectomy with bladder cancer. J Clin Oncol 22:1014-1024

52. Shariat SF, Lotan Y, Karakiewicz PI, Ashfaq R, Isbarn H, Fradet $\mathrm{Y}$ et al (2009) p53 predictive value for pT1-2 N0 disease at radical cystectomy. J Urol 182:907-913. https://doi.org/10.1016/j. juro.2009.05.024

53. Stadler WM, Lerner SP, Groshen S, Stein JP, Shi SR, Raghavan D et al (2011) Phase III study of molecularly targeted adjuvant therapy in locally advanced urothelial cancer of the bladder based on p53 status. J Clin Oncol 29:3443-3449. https://doi.org/10.1200/ jco.2010.34.4028

54. Chatterjee SJ, Datar R, Youssefzadeh D, George B, Goebell PJ, Stein JP et al (2004) Combined effects of p53, p21, and pRb expression in the progression of bladder transitional cell carcinoma. J Clin Oncol 22:1007-1013. https://doi.org/10.1200/ JCO.2004.05.174

55. Shariat SF, Karakiewicz PI, Ashfaq R, Lerner SP, Palapattu GS, Cote RJ et al (2008) Multiple biomarkers improve prediction of bladder cancer recurrence and mortality in patients undergoing cystectomy. Cancer 112:315-325. https://doi.org/10.1002/ cncr.23162

56. Shariat SF, Chromecki TF, Cha EK, Karakiewicz PI, Sun M, Fradet $\mathrm{Y}$ et al (2012) Risk stratification of organ confined bladder cancer after radical cystectomy using cell cycle related biomarkers. J Urol 187:457-462. https://doi.org/10.1016/j. juro.2011.10.031

57. Shariat SF, Ashfaq R, Sagalowsky AI, Lotan Y (2006) Correlation of cyclin D1 and E1 expression with bladder cancer presence, invasion, progression, and metastasis. Hum Pathol 37:1568-1576. https://doi.org/10.1016/j.humpath.2006.05.017

58. Shariat SF, Karakiewicz PI, Godoy G, Karam JA, Ashfaq R, Fradet $\mathrm{Y}$ et al (2009) Survivin as a prognostic marker for urothelial carcinoma of the bladder: a multicenter external validation study. Clin Cancer Res 15:7012-7019. https://doi.org/10.1158/10780432.CCR-08-2554

59. Zu X, Tang Z, Li Y, Gao N, Ding J, Qi L (2006) Vascular endothelial growth factor-C expression in bladder transitional cell cancer and its relationship to lymph node metastasis. BJU Int 98:10901093. https://doi.org/10.1111/j.1464-410X.2006.06446.x

60. Herrmann E, Eltze E, Bierer S, Köpke T, Görge T, Neumann J et al (2007) VEGF-C, VEGF-D and Flt-4 in transitional bladder cancer: relationships to clinicopathological parameters and longterm survival. Anticancer Res 27:3127-3133

61. Margulis V, Lotan Y, Karakiewicz PI, Fradet Y, Ashfaq R, Capitanio U et al (2009) Multi-institutional validation of the predictive value of Ki-67 labeling index in patients with urinary bladder cancer. J Natl Cancer Inst 101:114-119. https://doi.org/10.1093/ jnci/djn451

62. Margulis V, Shariat SF, Ashfaq R, Sagalowsky AI, Lotan Y (2006) Ki-67 is an independent predictor of bladder cancer outcome in patients treated with radical cystectomy for organconfined disease. Clin Cancer Res 12:7369-7373. https://doi. org/10.1158/1078-0432.CCR-06-1472

63. Bartsch G, Mitra AP, Cote RJ (2010) Expression profiling for bladder cancer: strategies to uncover prognostic factors. Expert Rev Anticancer Ther 10:1945-1954. https://doi.org/10.1586/ era. 10.131

64. Cancer Genome Atlas Research N (2014) Comprehensive molecular characterization of urothelial bladder carcinoma. Nature 507:315-322. https://doi.org/10.1038/nature12965

65. Oneyama C, Ikeda J, Okuzaki D, Suzuki K, Kanou T, Shintani $Y$ et al (2011) MicroRNA-mediated downregulation of mTOR/ FGFR3 controls tumor growth induced by Src-related oncogenic pathways. Oncogene 30:3489-3501. https://doi.org/10.1038/ onc. 2011.63

66. Mitra AP, Lerner SP (2015) Potential role for targeted therapy in muscle-invasive bladder cancer: lessons from the cancer genome atlas and beyond. Urol Clin North Am 42:201-215. https://doi. org/10.1016/j.ucl.2015.01.003

67. Shariat SF, Kim J, Nguyen C, Wheeler TM, Lerner SP, Slawin KM (2003) Correlation of preoperative levels of IGF-I and IGFBP-3 with pathologic parameters and clinical outcome in patients with bladder cancer. Urology 61:359-364

68. Kim JH, Shariat SF, Kim IY, Menesses-Diaz A, Tokunaga H, Wheeler TM et al (2001) Predictive value of expression of transforming growth factor- $\beta 1$ and its receptors in transitional cell carcinoma of the urinary bladder. Cancer 92:1475-1483. https://doi. org/10.1002/1097-0142(20010915)92:6\%3c1475:AID-CNCR1 472\%3e3.0.CO;2-X [pii]

69. Shariat SF, Kim JH, Andrews B, Kattan MW, Wheeler TM, Kim IY et al (2001) Preoperative plasma levels of transforming growth factor $\beta 1$ strongly predict clinical outcome in patients with bladder carcinoma. Cancer 92:2985-2992. https://doi.org/10.1002/10970142(20011215)92:12\%3c2985:AID-CNCR10175\%3e3.0.CO;2-5 [pii]

70. Andrews B, Shariat SF, Kim JH, Wheeler TM, Slawin KM, Lerner SP (2002) Preoperative plasma levels of interleukin-6 and its soluble receptor predict disease recurrence and survival of patients with bladder cancer. J Urol 167:1475-1481. https://doi. org/10.1016/S0022-5347(05)65348-7 [pii]

71. Masson-Lecomte A, Rava M, Real FX, Hartmann A, Allory Y, Malats N (2014) Inflammatory biomarkers and bladder cancer prognosis: a systematic review. Eur Urol 66:1078-1091. https:// doi.org/10.1016/j.eururo.2014.07.033

72. Mbeutcha A, Shariat SF, Rieken M, Rink M, Xylinas E, Seitz C et al (2016) Prognostic significance of markers of systemic inflammatory response in patients with non-muscle-invasive bladder cancer. Urol Oncol 34:483.e17-483.e24. https://doi.org/10.1016/j. urolonc.2016.05.013

73. Bernardini S, Fauconnet S, Chabannes E, Henry PC, Adessi G, Bittard H (2001) Serum levels of vascular endothelial growth factor as a prognostic factor in bladder cancer. J Urol 166:1275-1279. https://doi.org/10.1016/S0022-5347(05)65752-7 [pii]

74. Rink M, Chun FK, Minner S, Friedrich M, Mauermann O, Heinzer $\mathrm{H}$ et al (2011) Detection of circulating tumour cells in peripheral blood of patients with advanced non-metastatic bladder cancer. BJU Int 107:1668-1675. https://doi.org/10.1111/j.1464410X.2010.09562.X

75. Rink M, Chun FK, Dahlem R, Soave A, Minner S, Hansen J et al (2012) Prognostic role and HER2 expression of circulating tumor cells in peripheral blood of patients prior to radical cystectomy: a 
prospective study. Eur Urol 61:810-817. https://doi.org/10.1016/j. eururo.2012.01.017

76. Esrig D, Elmajian D, Groshen S, Freeman JA, Stein JP, Chen SC et al (1994) Accumulation of nuclear p53 and tumor progression in bladder cancer. N Engl J Med 331:1259-1264

77. Plimack ER, Dunbrack RL, Brennan TA, Andrake MD, Zhou Y, Serebriiskii IG et al (2015) Defects in DNA repair genes predict response to neoadjuvant cisplatin-based chemotherapy in muscle-invasive bladder cancer. Eur Urol 68:959-967. https://doi. org/10.1016/j.eururo.2015.07.009

78. Liu D, Plimack ER, Hoffman-Censits J, Garraway LA, Bellmunt J, Van Allen E et al (2016) Clinical validation of chemotherapy response biomarker ERCC2 in muscle-invasive urothelial bladder carcinoma. JAMA Oncol 2:1094-1096. https://doi.org/10.1001/ jamaoncol.2016.1056

79. Xu ZC, Cai HZ, Li X, Xu WZ, Xu T, Yu B et al (2016) ERCC1 C118T polymorphism has predictive value for platinum-based chemotherapy in patients with late-stage bladder cancer. Genet Mol Res. https://doi.org/10.4238/gmr.15027801

80. Iyer G, Hanrahan AJ, Milowsky MI, Al-Ahmadie H, Scott SN, Janakiraman M et al (2012) Genome sequencing identifies a basis for everolimus sensitivity. Science 338:221. https://doi. org/10.1126/science. 1226344

81. Rosenberg JE, Hoffman-Censits J, Powles T, van der Heijden MS, Balar AV, Necchi A et al (2016) Atezolizumab in patients with locally advanced and metastatic urothelial carcinoma who have progressed following treatment with platinum-based chemotherapy: a single-arm, multicentre, phase 2 trial. Lancet 387:19091920. https://doi.org/10.1016/S0140-6736(16)00561-4

82. Sharma P, Retz M, Siefker-Radtke A, Baron A, Necchi A, Bedke J et al (2017) Nivolumab in metastatic urothelial carcinoma after platinum therapy (CheckMate 275): a multicentre, single-arm, phase 2 trial. Lancet Oncol 18:312-322. https://doi.org/10.1016/ S1470-2045(17)30065-7

83. Bellmunt J, de Wit R, Vaughn DJ, Fradet Y, Lee JL, Fong L et al (2017) Pembrolizumab as second-line therapy for advanced urothelial carcinoma. N Engl J Med 376:1015-1026. https://doi. org/10.1056/NEJMoa1613683

84. Balar AV, Galsky MD, Rosenberg JE, Powles T, Petrylak DP, Bellmunt $\mathbf{J}$ et al (2017) Atezolizumab as first-line treatment in cisplatin-ineligible patients with locally advanced and metastatic urothelial carcinoma: a single-arm, multicentre, phase 2 trial. Lancet 389:67-76. https://doi.org/10.1016/S0140-6736(16)32455-2

85. Powles T, O'Donnell PH, Massard C, Arkenau HT, Friedlander TW, Hoimes CJ et al (2017) Efficacy and safety of durvalumab in locally advanced or metastatic urothelial carcinoma: updated results from a phase 1/2 open-label study. JAMA Oncol. https:// doi.org/10.1001/jamaoncol.2017.2411

86. Apolo AB, Infante JR, Balmanoukian A, Patel MR, Wang D, Kelly K et al (2017) Avelumab, an anti-programmed death-ligand 1 antibody, in patients with refractory metastatic urothelial carcinoma: results from a multicenter, phase Ib study. J Clin Oncol 35:2117-2124. https://doi.org/10.1200/JCO.2016.71.6795

87. Sharma P, Callahan MK, Bono P, Kim J, Spiliopoulou P, Calvo $E$ et al (2016) Nivolumab monotherapy in recurrent metastatic urothelial carcinoma (CheckMate 032): a multicentre, open-label, two-stage, multi-arm, phase 1/2 trial. Lancet Oncol 17:15901598. https://doi.org/10.1016/S1470-2045(16)30496-X

88. Massard C, Gordon MS, Sharma S, Rafii S, Wainberg ZA, Luke $\mathrm{J}$ et al (2016) Safety and efficacy of durvalumab (MEDI4736), an anti-programmed cell death ligand- 1 immune checkpoint, in patients with advanced urothelial bladder cancer. J Clin Oncol 34:3119-3125. https://doi.org/10.1200/JCO.2016.67.9761

89. Xylinas E, Robinson BD, Kluth LA, Volkmer BG, Hautmann R, Küfer R et al (2014) Association of T-cell co-regulatory protein expression with clinical outcomes following radical cystectomy for urothelial carcinoma of the bladder. Eur J Surg Oncol 40:121127. https://doi.org/10.1016/j.ejso.2013.08.023

90. Shariat SF, Gust KM (2017) Immune therapy meets precision medicine. Lancet Oncol 18:271-273. https://doi.org/10.1016/ S1470-2045(17)30098-0 